\title{
Environmental flows for natural, hybrid, and novel riverine ecosystems in a changing world
}

\author{
Mike Acreman ${ }^{1 *}$, Angela H Arthington ${ }^{2}$, Matthew J Colloff ${ }^{3}$, Carol Couch ${ }^{4}$, Neville D Crossman ${ }^{5}$, Fiona Dyer ${ }^{6}$, \\ Ian Overton ${ }^{7}$, Carmel A Pollino ${ }^{4}$, Michael J Stewardson ${ }^{8}$, and William Young, ${ }^{4,9}$
}

The term "environmental flows" describes the quantities, quality, and patterns of water flows required to sustain freshwater and estuarine ecosystems and the ecosystem services they provide. Environmental flows may be achieved in a number of different ways, most of which are based on either (1) limiting alterations from the natural flow baseline to maintain biodiversity and ecological integrity or (2) designing flow regimes to achieve specific ecological and ecosystem service outcomes. We argue that the former practice is more applicable to natural and semi-natural rivers where the primary objective and opportunity is ecological conservation. The latter "designer" approach is better suited to modified and managed rivers where return to natural conditions is no longer feasible and the objective is to maximize natural capital as well as support economic growth, recreation, or cultural history. This permits elements of ecosystem design and adaptation to environmental change. In a future characterized by altered climates and intensive regulation, where hybrid and novel aquatic ecosystems predominate, the designer approach may be the only feasible option. This conclusion stems from a lack of natural ecosystems from which to draw analogs and the need to support broader socioeconomic benefits and valuable configurations of natural and social capital.

Front Ecol Environ 2014; 12(8): 466-473, doi:10.1890/130134 (published online 26 Aug 2014)

W ater management has historically focused on direct resource benefits (eg for domestic use, growing food, generating power, supporting industry) to people through economic growth or poverty alleviation. Nevertheless, many global initiatives (eg MA 2005) have highlighted the link between biodiversity, ecosystems, and human well-being. Thus, providing water for the

\section{In a nutshell:}

- The term "environmental flows" defines the water needed within managed rivers to support important ecological processes and the human well-being provided by the ecosystem

- The basis of many methods used to calculate environmental flow is to get as close as is practical to flow regimes that were present before river system regulation

- In heavily regulated river systems, there are lower expectations of a return to "naturalness", leading to flow regimes designed to maximize natural capital and to produce broader socioeconomic benefits

- In an altered climate and under intense river management, hydrological and ecological change is inevitable and future flow regimes should not be constrained to attempts to reinstate historical conditions

- Designer river flows and adaptive management systems may become the norm as natural environments are replaced by managed systems offering novel but valuable collections of benefits to people

${ }^{1}$ Centre for Ecology and Hydrology, Crowmarsh Gifford, Wallingford, UK *(man@ceh.ac.uk); ${ }^{2}$ Australian Rivers Institute, Griffith University, Nathan, Australia; ${ }^{3} \mathrm{CSIRO}$ Ecosystem Sciences, Canberra, Australia; continued on p 473 environment indirectly supports people by maintaining ecosystems and a flow of benefits, termed "ecosystem services", from them (Fischer et al. 2009). Yet the degradation of freshwater ecosystems resulting from direct human use of water is increasing (Vörösmarty et al. 2010). The quantities, quality, and timing of water flows required to sustain freshwater and estuarine ecosystems and the services they provide to people are termed "environmental flows" (Brisbane Declaration; www.eflownet.org).

Initially, the definition of environmental flows was based on the need for minimum low flows, since this is considered the limiting factor for maintaining a healthy river ecosystem (Acreman and Dunbar 2004). However, it is now widely recognized that all elements of the flow regime - including floods and low or zero flows - play a role in influencing the biodiversity and functions of freshwater ecosystems (Bunn and Arthington 2002), with too much flow at the wrong time of year or season being just as detrimental as too little flow. Early environmental flow methods focused on valued indicator species ("assets"), assuming that if conditions were appropriate for the most sensitive of these organisms, other species and assemblages would be conserved. Yet the complexity of food webs and feedback loops necessitates targeting a range of species - including plants, fish, algae, invertebrates, reptiles, amphibians, and birds - spanning wide ecological requirements. Most methods now take a holistic systems approach to include a multitude of flow variables representing the whole flow regime, to conserve the major elements of the aquatic ecosystem (ie the preservation of biodiversity and ecosystem integrity). A further 
methodological development has concentrated on the ecosystem per se - in which benefits to people are indirect and with the explicit aim of maintaining the socially valued benefits of ecosystems. Consistent with this trend, various paradigms have been developed to support the concept of environmental flows with (1) an ecological focus and (2) an explicit human focus. This paper describes a new framework for considering the range of environmental flow approaches and focuses on the role of designing flow regimes to support socially defined novel ecosystems and valuable configurations of natural capital as the best future management option in a changing world.

\section{The natural flow regime paradigm}

Taking the natural system as its starting point, the natural flow regime paradigm (Poff et al. 1997) states that the natural dynamic character of the flow regime of a river described by six components: magnitude, frequency, duration, timing, rate of change, and overall variability of flow - is central to sustaining biodiversity and ecosystem integrity. It argues that organisms adapted and communities were assembled and are now maintained under the natural flow regime (Lytle and Poff 2004). Modification of the natural flow regime can adversely affect riverine, riparian, and floodplain species and processes, and there are limits to hydrological change beyond which substantial (or unacceptable) ecological alteration takes place (Richter et al. 1997; Arthington et al. 2006).

The natural flow regime is best defined by recorded historical flow data that predates development. Some countries, such as the US, have flow records prior to 1900 . However, many river flow records began in the 1960s, thus providing approximately 50 years of data. Analysis of flow records for the River Thames (since 1850), for example, show that flows since the early 1960s are not representative of variations over the longer period (Hannaford and Marsh 2006). Paleo-hydrological studies can offer limited evidence of hydrological conditions that occurred hundreds or thousands of years ago but cannot be used to reconstruct long-term flow records. In place of truly natural flows, "naturalized" flows are often used as a baseline produced by hydrological models in which the effects of major water withdrawals, diversions, and discharges have been removed. The impacts of past landscape or land-use changes are less often included in such models. The idea of the natural hydrological baseline is explicit in the Ecological Limits of Hydrologic Alteration (ELOHA) framework (Poff et al. 2010). Scenarios of flow (recorded, modeled, or hypothesized) can then be compared with this baseline condition. Even at river gauging stations, discharge is rarely measured to within an accuracy of less than $10 \%$, especially during high and low flows, and modeled flows will be far more uncertain. Assessment of differences in flow regimes between naturalized and regulated scenarios must recognize these sources of uncertainty.

In the natural flow paradigm, the baseline flow regime provides the starting point against which the ecological effects of removing or changing particular flow elements (such as reducing high flows) can be predicted or hypothesized. The increasing risk of ecological changes with increasing magnitude of alteration in flows has been demonstrated for some organisms (eg fish, waterfowl). This paradigm focuses on maintenance of biodiversity and basic ecological processes that underpin natural delivery of ecosystem services. The approach is perhaps most clearly applicable to rivers of high conservation value, where a primary objective is to maintain a near-natural river flow regime to support a near-pristine riverine ecosystem. For instance, under the European Water Framework Directive, the target for such rivers is High Ecological Status, where flows should not vary from the natural regime by more than 5\% (Acreman and Ferguson 2010). An argument in favor of this approach is that because all elements of the flow regime are important in maintaining the riverine ecosystem, calculation of a comprehensive suite of hydrological parameters (magnitude, timing, frequency, duration, variability) provides a reliable surrogate indicator of ecosystem condition. Conditions for natural species and communities may therefore be maintained by ensuring that the flow regime retains many of its natural characteristics. However, such relationships are often complicated by other pressures such as impaired water quality, particularly temperature regimes and dissolved oxygen levels.

\section{The designer paradigm}

Much of the Earth's habitable land surface has been artificially managed for millennia, as human populations have expanded and land use has intensified. Water-resource management, including major infrastructure such as dams, is seen as essential to alleviate poverty, mitigate flooding risks to people and property, and generate hydropower. It must be accepted that change in flow regimes is inevitable and historical natural conditions typically cannot be reinstated. In many cases, environmental flows aim to support local rural livelihoods, such as in the Senegal, Logone, and Kafue river systems of Africa, where annual floods provide natural irrigation to floodplain agriculture, fisheries, and cattle grazing. This illustrates the specific human well-being objectives and sustainable development outcomes that environmental flows can deliver, as covered by the Brisbane Declaration definition.

Heavily regulated river systems are not without ecological value. In 2012, Tunisia designated six reservoirs including Barrage de Sidi El Barrak, which stores irrigation water and provides potable water to the city of Tunis, yet supports the threatened Eurasian otter (Lutra lutra) as wetlands of international importance under the Ramsar Convention. The River Itchen, in the UK, is designated under the European Habitats Directive for its unique aquatic vegetation communities and also delivers a wide range of ecosystem services, chiefly recreation and cultural heritage. Yet the river is largely artificial, charac- 


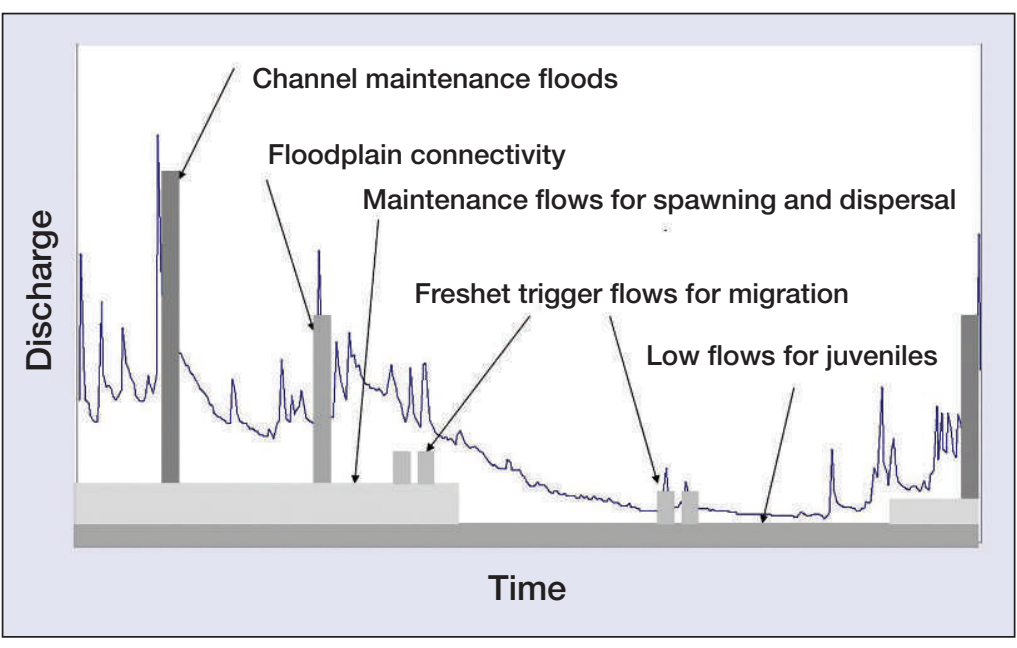

Figure 1. Components of the flow regime required to deliver specific ecosystem functions (after Acreman et al. 2009).

terized by channel widening and deepening to reduce flooding of riparian land, and is regulated by weirs and sluice gates associated with historic mills. Water has been pumped from aquifers and diverted to and from the river for many centuries. The assessment of environmental flows has focused on maintenance of this altered but valued river ecosystem and natural flow regime is not considered an appropriate baseline; instead, a recent historical baseline is used for the period before major new abstractions were introduced. Such socially desired ecosystems may not always be considered appropriate from a purist ecological perspective.

The recognition by society that rivers provide a wide range of ecosystem services, often associated with major infrastructure and altered flow regimes, has led some countries to set a range of environmental objectives. In the US state of Connecticut, every river reach is assigned a condition goal class from 1 to 4 . Class 1 streams support habitat conditions and biological communities typical of free-flowing streams. Class 2 and 3 streams support "minimally altered" and "moderately altered" biological communities, respectively. Class 4 streams are recognized as being substantially modified. A similar classification scheme is used in South Africa, where each river is assigned a management class through a process of research, stakeholder consultation, and negotiation: Class 1 (Minimally used), Class 2 (Moderately used), or Class 3 (Heavily used). Each of these classes has different baselines and targets for restoration and maintenance as well as baselines to assess long-term trajectories of change. Under the European Water Framework Directive, natural river waterbodies need to achieve "Good Ecological Status", whereas "Good Ecological Potential" is the target for heavily modified waterbodies.

A series of environmental flow approaches has been developed that design the river's flow regime to help deliver valued or desired species, communities, functions, and ecosystem services (Acreman and Dunbar 2004; Arthington 2012). Flow manipulation may be under- taken through the use of channel infrastructure or pumping, for instance to enable floodplain inundation at lower flows than would be needed naturally to sustain iconic conservation sites along the Murray River in Australia (Vilizzi et al. 2013). Flow regimes may also be designed to prevent the system from moving to a different ecological condition or to counteract unwanted invasive species or algal blooms. This approach can start with a non-natural flow baseline, such as for the River Itchen example described above. Alternatively, it can start, at least conceptually, with no flow (the situation below a dam with the outlet gates closed). Specific flow elements (eg summer low flows and spring floods) are defined to deliver particular objectives, such as fish migration and spawning, or wetting of channel backwaters to provide fish rearing habitat (Figure 1). These elements are combined into a flow regime that, as far as possible, meets all specified objectives and desirable ecological and social outcomes, such as recreation or cultural heritage. Implementation often involves releasing water from storage infrastructure (eg reservoirs) that otherwise disrupts the flow regime. The most well-known framework is the Building Block Methodology, developed in South Africa (King et al. 2000) but widely applied (Figure 1; Acreman and Ferguson 2010). In some applications the total environmental water allocation volume is agreed through a political process, and scientific understanding is used to distribute this volume effectively as a flow regime to meet society's objectives for the river. The practicality of this approach depends upon the degree of control offered by a dam (ie the relative size of the river and dam). For small dams on large rivers, the ability to design and implement a flow regime is limited because much of the water may bypass the main channel via spillways. However, even on large rivers - if the infrastructure is large enough, as in the case of the Three Gorges Dam on the Yangtze River in China - sufficient control may be in place to fully design the downstream environmental flow regime.

The idea of being able to define and quantify the components of the flow hydrograph and assemble them into an environmental flow regime that meets a particular set of ecological and social objectives can be thought of as a "designer" approach, producing environmental flows that support desired ecosystem states or provide desired ecosystem services. The inherent risk is that although superficially the direct relationships between flow characteristics (eg flood duration and extent) and broad-scale river ecosystem attributes (eg condition of floodplain forests, fish abundance) may be represented by simple rules, the final constructed flow regime may lack crucial characteristics that support underpinning ecosystem functions in complex indirect ways (eg by controlling microbiological processes, food web connectivity, or bio- 
geochemical interactions; Baldwin et al. 2013). A designed ecosystem may not be sustainable without considerable management input. Furthermore, flow components are not independent and may interact to create ecological opportunities for some species and limitations for others. The application of the designer approach carries with it the responsibility of the environmental flow practitioner to optimize the design and manage any tradeoffs. Finally, because the ecosystem will continue to adapt under the new regime, and water availability may be constrained by land-use activities and climate change (Palmer et al. 2008), the watering regime may need to be modified periodically through adaptive management (Walters 1986) to avoid creating ecological "museums" that are difficult or impossible to maintain.

\section{Natural or designed?}

In both the natural regime and the designer flow paradigms there is an underlying assumption that the desired ecosystem may not need a fully natural flow hydrograph and that some flow characteristics can be altered to some degree, or even "left out". Much depends on the sensitivity of the ecosystem to hydrological alteration, but if the flow regime is changed substantially, the river ecosystem is likely to be different from its natural condition and may deliver a modified suite of ecosystem services. Whether the new ecosystem is desirable or undesirable is a matter of social choice, which may be influenced by historical decisions or future expectations. This conclusion suggests that the most widely applicable aspects of the natural flow paradigm are the words "flow paradigm", because all elements of the flow regime will have an influence over the resulting river ecosystem, whether natural or designed. We argue that if the aim is for a natural ecosystem, a natural flow regime (or a regime minimally altered from natural) is required, whereas if the aim is a particular ecosystem state or set of services, then a designed flow regime is needed (Table 1 ). In Table 2 we provide some examples of rivers from different regions of the world, where the natural and designer flow paradigms have been implemented. The sociopolitical challenge is how to decide whether a natural or designed system is preferred by society. But the scientific challenge is to define flow-ecological response relationships in which ecological changes (both detrimental and beneficial) caused by flow alteration can be specified and quantified (Poff et al. 2010; Davies et al. 2014).

Table 1. Essential roles of different environmental flow approaches

\begin{tabular}{lll}
\hline Defining characteristics & Natural flow regime paradigm & Designer flow paradigm \\
\hline River/catchment type & Protected areas and near-natural & Rivers with high, competing water demands, \\
& flow regimes & over-allocated river systems, severely altered \\
& flow regimes, highly modified morphology and \\
& ecology, hybrid and novel ecosystems
\end{tabular}

\begin{tabular}{|c|c|c|}
\hline $\begin{array}{l}\text { Type of water resource } \\
\text { development }\end{array}$ & $\begin{array}{l}\text { Unregulated rivers, or those with } \\
\text { minor direct river abstractions, or } \\
\text { small weirs }\end{array}$ & $\begin{array}{l}\text { Rivers with major flow regime changes due to } \\
\text { dam operations, abstractions, or diversions }\end{array}$ \\
\hline Ecosystem objectives & $\begin{array}{l}\text { Conservation of current natural or } \\
\text { near-natural ecosystems and } \\
\text { maintaining ecological security }\end{array}$ & $\begin{array}{l}\text { Multiple values and benefits, economic growth, } \\
\text { food security, energy, moderate to highly } \\
\text { modified ecosystems and landscapes }\end{array}$ \\
\hline $\begin{array}{l}\text { Environmental flow } \\
\text { objectives }\end{array}$ & $\begin{array}{l}\text { Natural flow regime and ecosystem } \\
\text { target }\end{array}$ & Designer flow regime and ecosystem targets \\
\hline Implementation & $\begin{array}{l}\text { Long-term, hind-casting, statistical } \\
\text { assessment of flow regimes, } \\
\text { monitoring, and adaptive management } \\
\text { of flow allocations }\end{array}$ & $\begin{array}{l}\text { Day-to-day management of novel designed flow } \\
\text { regimes, monitoring, and adaptive management } \\
\text { of flow allocations }\end{array}$ \\
\hline Drought management & $\begin{array}{l}\text { Include droughts and low flows as part } \\
\text { of the natural flow regime and } \\
\text { ecological processes }\end{array}$ & $\begin{array}{l}\text { Provide additional flow during long dry periods } \\
\text { to maintain targeted species and ecosystem } \\
\text { services }\end{array}$ \\
\hline Flood pulse management & $\begin{array}{l}\text { Ensure natural sediment processes } \\
\text { and landscape evolution }\end{array}$ & Ensure connectivity of river and floodplain \\
\hline Environmental targets & $\begin{array}{l}\text { Whole ecosystem, species, } \\
\text { communities, and ecological processes }\end{array}$ & $\begin{array}{l}\text { Target habitats, species, or goods and ecosystem } \\
\text { services }\end{array}$ \\
\hline Management approach & $\begin{array}{l}\text { Produce water sharing plans, establish } \\
\text { limits to abstraction or diversion, } \\
\text { conserve self-managing ecosystems }\end{array}$ & $\begin{array}{l}\text { Define limits to abstraction, prescribe dam } \\
\text { releases, permit active water management and } \\
\text { water trading }\end{array}$ \\
\hline
\end{tabular}


Regardless of the approach, a particular difficulty is the identification of thresholds of hydrological alteration at which important ecological change occurs (Poff et al. 2010). Some thresholds are evident in riverine ecosystems, such as when the river channel is full to capacity and any additional discharge causes water to spill onto the floodplain. At this point the river and floodplain become hydrologically connected, which can be very important to the functions of the ecosystem, such as expanded habitat and food resources to support fish recruitment or to maintain plant species diversity, condition, and ecosystem resilience (Colloff and Baldwin 2010). Other ecological thresholds may be more difficult to identify and quantify or may not exist, because many ecohydrological relationships appear linear or form smooth curves (eg Figure 2) and the decisive limits of hydrologic alteration may have to be evaluated as "thresholds of concern" (Biggs and Rogers 2003) or by some form of expert consensus (Acreman and Ferguson 2010; Poff et al. 2010). At a more fundamental level, ecohydrological response curves typically do not incorporate population processes (Lancaster and Downes 2010) or ecological feedbacks (Anderson et al. 2006) that govern fecundity, recruitment, and mortality and thus have limited capacity to simulate rates of decline and recovery of species and biological communities from hydrological change, particularly in response to extreme events such as droughts. Coupling of hydrological models and population models (eg for fish; Shenton et al. 2012) may provide a more thorough mechanistic understanding and way forward.

Although the natural and designer flow paradigms might begin at opposite extremes, we often see a convergence to a common end. On the one hand, some characteristics of the natural flow regime may be foregone if the remaining flow regime stays within limits that can maintain ecosystem elements. On the other hand, if environmental flows are designed to help deliver a wide array of ecosystem elements, then the flow regime may need to include almost all of the "building blocks" available. The resulting flow regime may be much the same in the two cases. In practice, the natural flow paradigm may be more applicable to unregulated rivers facing water withdrawals

Table 2. Examples of river systems, extent of regulation, and associated environmental flow management paradigm

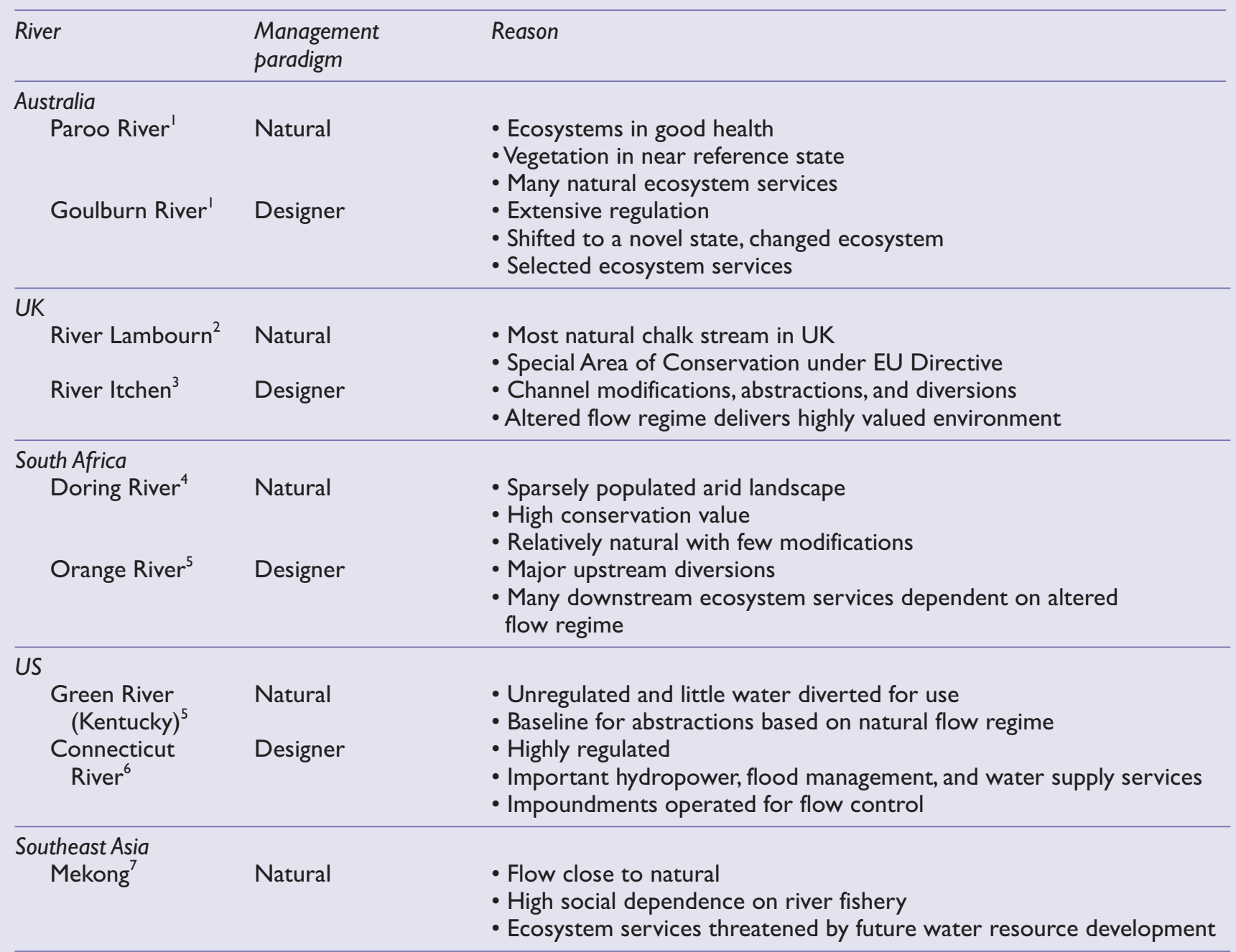

Notes: 'Davies et al. (2012); ${ }^{2}$ Grapes et al. (2005); ${ }^{3}$ Booker et al. (2004); ${ }^{4}$ King and Brown (2010); ${ }^{5}$ Warner et al. (2014); ${ }^{6}$ Kendy et al. (2012); ${ }^{7}$ Thompson et al. (2014). 
for direct human use, whereas the designer paradigm may be more appropriate where a heavily modified river is to be subjected to increasing allocations to the environment and associated ecosystem services.

\section{Novel ecosystems}

In many regions experiencing anthropogenic pressures (including shifting climates), the natural flow regimes that govern freshwater and estuarine ecosystems have been replaced by altered flow regimes. For example, more than half of the world's largest rivers, particularly in China, Southeast Asia, Brazil, and Africa, are already heavily regulated (Nilsson et al. 2005). By mid-century, annual average river runoff and water availability are projected to increase by

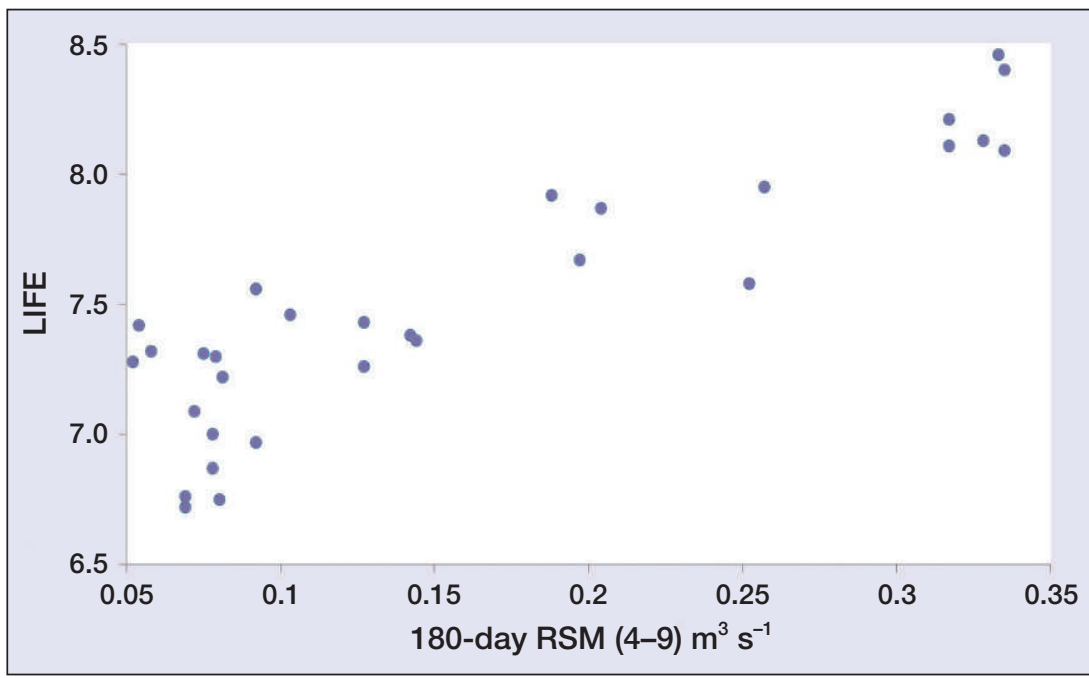

Figure 2. Scatterplot of Lotic Invertebrate Index for Flow Evaluation (LIFE) scores against flow (expressed as a 180-day running summer mean [RSM] Apr-Sep), from the Waithe Beck watercourse near the town of Brigsley, UK (after Extence et al. 1999).
$10-40 \%$ at high latitudes and in some wet tropical areas, and to decrease by $10-30 \%$ across some dry regions at mid-latitudes and in the dry tropics. Drought-affected areas will expand and heavy precipitation events are likely to become more common, thereby increasing flood risk (IPCC 2007). The combination of climate change and flow regulation is now exceeding paleo-shifts in flow regimes. Just how each aquatic ecosystem and species will respond depends on the characteristics of the new climate and its impacts on the variability of water and other environmental regimes, on land and in water.

The development of ecosystems that differ in species composition and ecological functions from past and present systems is increasingly recognized (Hobbs et al. 2006), often in relation to changing climates, the spread of alien invasive species into new areas, or the range shifts of native species. Some changes will result in development of hybrid systems that retain some original as well as novel characteristics. In this context, descriptive terms coming into frequent use include "emerging", "hybrid", "no-analog", and "novel" ecosystems (Hobbs et al. 2009). Climate change in particular provides potential for structurally novel ecosystems to emerge; these may require new thinking in advance of their development and a range of management approaches for systems that could face increasingly uncertain futures (Palmer et al. 2008). Seastedt et al. (2008) concluded that most ecosystems are now sufficiently altered in structure and function to qualify as novel systems and this recognition should be the starting point for ecosystem management efforts because otherwise the functions and services that remain will be at risk.

We argue that river ecosystems are partly defined by external forces of climate, land use, and water management, with a succession from natural, through managed or hybrid, to novel ecosystems as these forces change from their original patterns. This sequence of changes will continue in the future and may have substantial effects (Thomas et al. 2004) but, as ecosystems reach a new state with new forces (eg altered climate and flow regimes), a new "natural" flow regime will emerge in some regions. Likewise, previously undescribed forms of hybrid and novel ecosystems are also likely to emerge as each ecosystem adjusts to both the changing climate and management drivers. The new natural flow regime in a relatively pristine area may still provide the basis for environmental flow assessment through the use of a natural flow framework. However, hybrid and novel ecosystems that undergo further change under new climatic conditions and societal pressures may present new ecological outcomes and different societal compromises and choices. Designer frameworks that set out to deliver chosen ecosystem components and services will be required to provide hybrid and novel aquatic ecosystems. Resource managers need to accept that change is inevitable and must adapt, rather than constrain flow regimes to those that were defined by historical conditions.

\section{Adaptive management}

The natural flow regime paradigm was originally presented as a benchmark for river ecosystem conservation and restoration. Defining the flow regime elements that sustain assemblages and functions of an ecosystem is the cornerstone of river management, whatever the "desired future state" of that ecosystem may be. These ecohydrological relationships remain uncertain; nevertheless, the better we understand those relationships in today's and tomorrow's natural, hybrid, and novel ecosystems, the more accurately we will be able to predict the ecological implications of shifts in climatic and water regimes and human pressures on water resources. For instance, we now 
know that ecological communities can be relatively stable for long periods of time and then transition rapidly to a novel state, often as a result of disturbances such as floods (McMullen and Lytle 2012) and droughts (Bogan and Lytle 2011). Understanding these transitions and adapting water management practices is imperative as ecological and social systems evolve under novel environmental conditions. Characterized by effective monitoring, evaluation, and progressive alteration of flow releases or water withdrawals, adaptive management underpins delivery of the designer flow paradigm and links ecological targets with outcomes. Implementation of the natural flow approach may also benefit from adaptive management because the degree to which the flow regime can be altered without substantial ecological change may be uncertain. Above all, well-designed monitoring of ecological outcomes over time in every system receiving an environmental flow is the surest way to advance understanding of the ecological roles of flow, and to improve water use for the benefit of both ecosystems and humans (Davies et al. 2014).

\section{Conclusions}

Although some 250 methods for addressing environmental flows have been developed, most fall into one of two categories: (1) limited alteration from a natural flow regime baseline to maintain biodiversity and ecological integrity or (2) construction of a flow regime required to achieve specific outcomes and values from ecosystems and their services. The subtleties of individual methods relate to applications under particular local circumstances. The development of these two broad approaches enhances and clarifies the fundamental concepts and methods of environmental flow assessment (Acreman et al. 2014), but may polarize practitioners into two ideological camps. In contrast, we suggest that the two approaches are complementary and consistent, united by the need to understand and quantify relationships between flow regimes (whether natural or altered) and ecological responses and by the desire to manage river systems to deliver ecosystem services (including biodiversity protection), while safeguarding those systems from undesirable alteration. We recognize a range of conditions for the world's rivers, depending on the degree of water management, from totally unregulated to heavily regulated, as well as some for which environmental flows have been implemented. The natural flow regime approach is more applicable to natural and semi-natural rivers where the primary objective and opportunity is ecological conservation, with as little change as possible to the underlying natural flow regime. Conversely, the designer approach suits regulated and managed rivers where objectives may include deregulation and restoration of valued biodiversity, ecosystem integrity, and human-focused ecosystem services such as economic growth, recreation, or protection of cultural history. This latter approach also permits elements of ecosystem design and adaptation to environmental change. However, in a future characterized by further water abstractions, diversions, and impoundments together with major climatechange impacts on flow regimes, novel aquatic ecosystems may predominate and the designer approach may become the only feasible strategy because of insufficient examples of natural ecosystems and flow regimes from which to draw analogs. Furthermore, we believe that a stronger focus of environmental flow management on broader socioeconomic benefits as well as valuable configurations of natural and social capital may resonate better with members of the sustainable development community.

\section{Acknowledgements}

MA acknowledges financial support from a CSIRO Flagship Scholarship and the Natural Environment Research Council for the opportunity to work in Australia with the other authors. MJS acknowledges support from the Australian Research Council (ARC Project LP100200170).

\section{References}

Acreman MC and Dunbar MJ. 2004. Defining environmental river flow requirements - a review. Hydrol Earth Syst Sc 8: 861-76.

Acreman MC and Ferguson A. 2010. Environmental flows and the European Water Framework Directive. Freshwater Biol 55: $32-48$.

Acreman MC, Aldrick J, Binnie C, et al. 2009. Environmental flows from dams: the Water Framework Directive. Proc ICE Eng Sustain 2: 13-22.

Acreman MC, Overton I, King J, et al. 2014. The changing role of eco-hydrological science in guiding environmental flows. Hydrol Sci J 59: 433-50.

Anderson KE, Paul AJ, McCauley E, et al. 2006. Instream flow needs in streams and rivers: the importance of understanding ecological dynamics. Front Ecol Environ 4: 309-18.

Arthington AH. 2012. Environmental flows: saving rivers in the Third Millennium. Berkeley, CA: University of California Press.

Arthington AH, Bunn SE, Poff NL, and Naiman RJ. 2006. The challenge of providing environmental flow rules to sustain river ecosystems. Ecol Appl 16: 1311-18.

Baldwin DS, Rees GN, Wilson JS, et al. 2013. Provisioning of bioavailable carbon between wet and dry periods in a semi-arid floodplain. Oecologia 172: 539-50.

Biggs HC and Rogers KH. 2003. An adaptive system to link science, monitoring and management in practice. In: Du Toit JT, Rogers KH, and Biggs HC (Eds). The Kruger experience: ecology and management of savanna heterogeneity. Washington, DC: Island Press.

Bogan MT and Lytle DA. 2011. Severe drought drives novel community trajectories in desert stream pools. Freshwater Biol 56: 2070-81.

Booker DJ, Dunbar MJ, Acreman MC, et al. 2004. Habitat assessment at the catchment scale: application to the River Itchen, UK. In: Webb B, Arnell NW, Kirby C, et al. (Eds). Hydrology: science and practice for the 21st century, vol II, Proceedings of the British Hydrological Society International Conference; 12-16 Jul 2004; London, UK. London, UK: British Hydrological Society.

Bunn SE and Arthington AH. 2002. Basic principles and ecological consequences of altered flow regimes for aquatic biodiversity. Environ Manage 30: 492-507. 
Colloff MJ and Baldwin DS. 2010. Resilience of floodplain ecosystems in a semi-arid environment. Rangeland J 32: 305-14.

Davies PE, Stewardson MJ, Hillman TJ, et al. 2012. Sustainable rivers audit 2: the ecological health of rivers in the Murray-Darling Basin at the end of the Millennium Drought (2008-2010). Vol 1. Canberra, Australia: Murray-Darling Basin Authority.

Davies PM, Naiman RJ, Warfe DM, et al. 2014. Flow-ecology relationships: closing the loop on effective environmental flows. Mar Freshwater Res 65: 133-41.

Extence C, Balbi DM, and Chadd RP. 1999. River flow indexing using British benthic macro-invertebrates: a framework for setting hydro-ecological objectives. Regul River 15: 543-74.

Fischer B, Turner RK, and Morling P. 2009. Defining and classifying ecosystem services for decision making. Ecol Econ 68: 643-53.

Grapes TR, Bradley C, and Petts GE. 2005. Dynamics of river-aquifer interactions along a chalk stream: the River Lambourn, UK. Hydrol Process 19: 2035-53.

Hannaford J and Marsh TJ. 2006. An assessment of trends in UK runoff and low flows using a network of undisturbed catchments. Int J Climatol 26: 1237-53.

Hobbs RJ, Arico S, Aronson J, et al. 2006. Novel ecosystems: theoretical and management aspects of the new ecological world order. Global Ecol Biogeogr 15: 1-7.

Hobbs RJ, Higgs E, and Harris JA. 2009. Novel ecosystems: implications for conservation and restoration. Trends Ecol Evol 24: 599-605.

IPCC (Intergovernmental Panel on Climate Change). 2007. In: Pachauri RK and Reisinger A (Eds). Climate change 2007: synthesis report. Contribution of Working Groups I, II, and III to the Fourth Assessment Report of the Intergovernmental Panel on Climate Change. Geneva, Switzerland: IPCC.

Kendy E, Apse C, Blann K, et al. 2012. A practical guide to environmental flows for policy and planning, with nine case studies from the United States. Arlington, VA: The Nature Conservancy.

King JM and Brown CA. 2010. Integrated basin flow assessments: concepts and method development in Africa and Southeast Asia. Freshwater Biol 55: 127-46.

King JM, Tharme RE, and de Villiers MS (Eds). 2000. Environmental flow assessments for rivers: manual for the Building Block Methodology. Pretoria, South Africa: Water Research Commission. Report TT 131/00.

Lancaster J and Downes BJ. 2010. Linking the hydraulic world of individual organisms to ecological processes: putting ecology into eco-hydraulics. River Res Appl 26: 385-403.

Lytle DA and Poff NL. 2004. Adaptation to natural flow regimes. Trends Ecol Evol 19: 94-100.

MA (Millennium Ecosystem Assessment). 2005. Ecosystems and human well-being: synthesis. Washington, DC: Island Press.
McMullen LE and Lytle DA. 2012. Quantifying invertebrate resistance to floods: a global-scale meta-analysis. Ecol Appl 22: $12-25$.

Nilsson C, Reidy CA, Dynesius M, and Revenga C. 2005. Fragmentation and flow regulation of the world's large river systems. Science 308: 405-08.

Palmer M, Reidy Liermann C, Nilsson C, et al. 2008. Climate change and the world's river basins: anticipating management options. Front Ecol Environ 6: 81-89.

Poff NL, Allan JD, Bain MB, et al. 1997. The natural flow regime: a paradigm for river conservation and restoration. BioScience 47: 769-84.

Poff NL, Richter BD, Arthington AH, et al. 2010. The ecological limits of hydrologic alteration (ELOHA): a new framework for developing regional environmental flow standards. Freshwater Biol 55: 147-70.

Richter BD, Baumgartner JV, Wigington R, and Braun DP. 1997. How much water does a river need? Freshwater Biol 37: 231-49.

Seastedt TR, Hobbs RJ, and Suding KN. 2008. Management of novel ecosystems: are novel approaches required? Front Ecol Environ 6: 547-53.

Shenton W, Bond NR, Yen JDL, and Mac Nally R. 2012. Putting the "ecology" into environmental flows: ecological dynamics and demographic modelling. Environ Manage 50: 1-10.

Thomas CD, Cameron A, Green RE, et al. 2004. Extinction risk from climate change. Nature 427: 145-48.

Thompson JR, Laize C, and Acreman MC. 2014. Climate change uncertainty in environmental flows for the Mekong River. Hydrolog Sci J 59: 1-20.

Vilizzi L, McCarthy BJ, Scholz O, et al. 2013. Managed and natural inundation: benefits for conservation of native fish in a semiarid wetland system. Aquat Conserv 23: 37-50.

Vörösmarty CJ, McIntyre PB, Gessner MO, et al. 2010. Global threats to human water security and river biodiversity. Nature 467: 555-61.

Walters CJ. 1986. Adaptive management of renewable resources. New York, NY: MacMillan.

Warner AT, Bach LB, and Hickey JT. 2014. Restoring environmental flows through adaptive reservoir management: planning, science, and implementation through the sustainable rivers project. Hydrolog Sci J 54: 770-85.

${ }^{4} \mathrm{CSIRO}$ Land and Water, Canberra, Australia; ${ }^{5} \mathrm{CSIRO}$ Ecosystem Sciences, Glen Osmond, Australia; ${ }^{6}$ Institute for Applied Ecology, University of Canberra, Canberra, Australia; ${ }^{7} \mathrm{CSIRO}$ Land and Water, Glen Osmond, Australia; ${ }^{8}$ Department of Infrastructure Engineering, University of Melbourne, Parkville, Australia; ${ }^{9}$ The World Bank, New Delhi, India

\section{TAKE THIS JOURNAL TO YOUR LIBRARIAN, PLEASE}

Are you enjoying this issue of Frontiers?

If your library had a subscription, colleagues and students could enjoy it too.

Please consider recommending Frontiers in Ecology and the Environment to your library. Clip or copy the form below. Thank you for your support.

Library Recommendation Form

To Acquisition Librarian, Serials

From

Dept

Signature

I recommend the library subscribe to: Frontiers in Ecology and the Environment (ISSN 1540-9295)

To request a free sample issue of Frontiers in Ecology and the Environment, email Eric Gordon at eric@esa.org.

Order Frontiers by contacting ESA Headquarters at (202) 833-8773, online at www.esa.org, or through your subscription agent. 